\title{
O USO DAS TECNOLOGIAS DE INFORMAÇÃO NA ESCOLA: DESAFIOS E POTENCIALIDADES NA PRÁTICA PEDAGÓGICA
}

\author{
*Gabriel César Dias Lopes
}

\section{RESUMO}

A aprendizagem é uma construção social, individual, mas também construída na coletividade e interatividade, buscando basicamente a cidadania, a inserção social e política adjacentes a essa, integrar ao processo de ensino as novas tecnologias e a utilização dos novos recursos da comunicação e da informação, fazem parte de um processo contínuo, acelerado e ascendente, que vão deliberando novas perspectivas, novos atores, novas relações, numa rapidez antes nunca vista na história da humanidade. A quantidade de informação trazida e a disponibilidade dessa parece ser ainda um desafio a ser superado pela educação escolar sem dúvida. Nesse sentido a inserção das mídias e tecnologia em geral em educação, trazem consigo o desafio e a possibilidade, uma vez que seu fazer potencializa o surgimento de um outro docente que não mais pronto e acabado como outrora, vai se formatando à medida que novos conhecimentos e interações são incorporadas à sua experiência, concomitante ao desenvolvimento do aluno, motivo primeiro e último de todo o fazer educacional. À luz de teóricos contemporâneos buscase aqui contextualizar a inserção e utilização das tecnologias midiáticas e de informação no fazer educacional nas escolas tendo em vista a busca incessante de uma aprendizagem mediatizada e significativa.

Palavras-chave: Comunicação. Tecnologia. Recursos Midiáticos, Aprendizagem Significativa.

\section{ABSTRACT}

Learning is a social construction, individual, but also built in the collectivity and interactivity, basically seeking citizenship, social and political insertion adjacent to it, integrating new technologies into the teaching process and the use of new communication and information resources, are part of a continuous, accelerated and ascending process, which deliberating new perspectives, new actors, new relationships, in a rapidity never seen before in the history of mankind. The amount of information brought and the availability of this seems to be still a challenge to be overcome by school education without a doubt. In this sense, the insertion of media and technology in general in education, bring with them the challenge and the possibility, 
since their doing enhances the emergence of another teacher who is no longer ready and finished as before, is being formatted as new knowledge and interactions are incorporated into his experience, concomitant with the development of the student, the first and last reason of all educational work. In the light of contemporary theorists, we seek to contextualize the insertion and use of media and information technologies in educational practice in schools in view of the incessant search for a mediated and meaningful learning.

Keywords: Communication. Technology. Media Resources. Meaningful Learning.

\begin{abstract}
* Gabriel Lopes - Mestre e Doutor em Educação, Mestre em Administração e PhD em Psicanálise. Graduação em Administração, Direito e Recursos Humanos. É pesquisador, autor, membro do Comitê Científico da Olympus Intellectual Center (Heptapolis), Atenas - Grécia. Pesquisas em Formação de Professores, Gestão na Docência, Direito e Relações Contratuais, Bipolaridade e conflito de diagnósticos em Psicanálise. Premiado pelo Presidente Barack Obama (President Award Education) no ano de 2016, Premiado com o moção de Distinção e Honra pela Contribuição da Educação pela Casa dos Representantes (Câmara de Deputados) do Estado do Texas. Fundador e Presidente da Logos University International, UniLogos, Professor Visitante da Pro Deo State University (New York-USA), Professor de Direito Internacional Comparado na City University (Camboja), Professor Visitante do Institute of Brain Chemistry \& Human Nutrition, IBCHN (Inglaterra).
\end{abstract}

\title{
INTRODUÇÃO
}

A temática desta investigação surgiu por considerar que tal questão, no cotidiano das salas de aula tem se constituído em uma das maiores dificuldades encontradas por muitos educadores em sua prática educativa. Esta dificuldade se constitui em motivo de preocupação para instituições escolares, profissionais da educação, de um, modo geral, e pais. A prática educacional, como toda e qualquer prática, faz surgir uma série de questões e especificamente no trato de problemas ligados à aprendizagem, levanta dificuldades que instigam com frequência os sujeitos envolvidos no processo educativo.

O que está em jogo, com certeza é um novo modelo de gestão da escola pública, em que se pressupõe a articulação com a sociedade imediata - bairro ou comunidade local, cidade - e vínculos mediatos com as esferas estaduais. Nesse sentido, permitem um contraponto aos diferentes tipos de problemas vivenciados, contribuindo para a melhoria do desempenho escolar e para a promoção da motivação de alunos e professores.

De certa forma, o modo como esses multimídias são implementadas, constituem por si só um problema, pois são colocadas de maneira certamente verticalizada, sem observar, ou talvez ignorando o contexto geral das escolas.

É nesse panorama que o debate sobre a utilização das multimídias na escola pública assume grande importância, pois se espera delas uma cultura escolar apta a lidar não só com a diversidade de seus alunos e com as desigualdades existentes entre eles, mas, também, a contribuir para a construção de uma escola mais igualitária em relação ao processo de transmissão do conhecimento e informação. 
Para mudar essa perspectiva é imprescindível que a comunidade escolar se responsabilize cotidianamente por garantir um ambiente de cooperação, abertura ao novo e disponibilidade em aprender. Exige assim, mudar hábitos, rever posturas, ressignificar experiências, refletir sobre as práticas, resgatar, reafirmar e/ou atualizar seus valores e, numa abordagem que tem um toque psicanalítico, colocar-se como parte responsável pelo processo em questão. O essencial é questionar e refletir acerca do que a escola está oferecendo a todos os alunos para fazer com que a aprendizagem ocorra de forma ativa, satisfatória e abrangente.

Em função desse contexto exposto acima, surge aqui a possibilidade de trabalhar essa problemática através da uma pesquisa bibliográfica com o propósito de investigar e compreender a relação entre a utilização das multimídias e a prática pedagógica que a escola oferece, explorando as razões subjacentes a essa relação para a partir deste entendimento desenvolver ações mais e mais eficazes que promovam uma mudança de olhar em relação às multimídias, estudando conceitos de desenvolvimento tecnológico e sua inserção cada dia mais contundente em nossa sociedade, inserindo juntamente uma postura ética, adotando-as como conhecimento necessário ao processo educacional.

A busca por uma educação humanista, é o pressuposto das tendências atuais da educação, nela a diversidade tecnológica é também percebida como uma dimensão complementar e não antagônica, provocando uma série de estudos que buscam refletir sobre o universo escolar como um fenômeno total, não mais determinado por uma ou outra dimensão (econômica, social e cultural), mas pela forma como estas dimensões afetam o cotidiano escolar. Inserir as multimídias na educação, é uma forma que quando usada corretamente, vai facilitar a visão desse processo como um todo, onde a análise das partes e dos detalhes são fundamentais,

Assim, recuperar os processos de integração social e de legitimidade do espaço da escola tem sido o grande desafio que mobiliza os diferentes setores que atuam ou refletem sobre o universo escolar. No âmbito da ação da escola, a busca por processos de integração social passa pela constituição de estratégias que visem à melhoria do clima escolar e a transformação da aprendizagem em algo prazeroso. Assim, integrar, incluir as multimídias são certamente pressuposto essenciais.

Para tanto busca-se aqui discutir sobre os paradigmas educacionais -ontem e hoje - e as possibilidades de formação de professores inseridos no processo educativo, ao uso das tecnologias digitais, neste momento onde a escola enfrenta o enorme desafio de inserir tecnologia atual de forma eficiente e eficaz, junto aos métodos de ensino usuais, seja substituindo-os, adequando-os, transformando-os, ou administrando o seu suposto uso.

Além da expressão oral, da leitura, da escrita e do cálculo, a escola deverá ensinar seus alunos a resolver problemas, isto é, a enfrentar as situações cada vez mais desafiadoras, complexas e exigentes com que eles têm de se defrontar na escola, na família e na comunidade, se quiserem realmente desenvolver o seu potencial como pessoa e como cidadãos. E para isso 
os multimídias são incorporadas, com a visão de facilitar o processo de transmissão de informações cada dia mais rápidas e inúmeras.

Comunicar e Educar complementam-se e, ao mesmo tempo, interagem pela independência. Quando se visa socializar e potencializar a formação de indivíduos. Nesse sentido, a tendência é ocorrer a união entre Educação e Comunicação, passando a configurar a Educomunicação.

Soares (2003), afirma que o educador tem como um dos seus grandes desafios colaborar para que a informação significativa possa premiar elementos basilares, no universo tão vasto das mesmas, e fomentar a compreensão dessas, na intenção de constituí-las com vetores abrangentes e perenes.

Este estudo surge da necessidade de atender as exigências do curso e discutir sobre o papel do professor como mediador do saber científico, sua postura perante novos paradigmas na educação, sua formação perante as mudanças tecnológicas numa perspectiva didática pedagógica.

Todo e qualquer recurso tecnológico deve ser concebido como estratégia plural na contribuição de melhorias das práxis pedagógica. Portanto, elabora-se esse artigo com um duplo propósito: de um lado procura-se dar um novo sentido à pesquisa junto aos alunos dentro da sala de aula; e, de outro, questionar e refletir sobre o trabalho desenvolvido junto aos alunos, e consequentemente entendendo melhor a ação do professor com a inserção das novas tecnologias de ensino em sala de aula.

\section{AS TECNOLOGIAS DIGITAIS E AS NOVAS TENDENCIAS EDUCACIONAIS}

O avanço tecnológico produz uma realidade sui generis na educação: o processo ensinoaprendizagem mediado por objetos que substituem o antigo binômio professor/aluno, ou por que não dizer, enriquece-o, subsidia-o com o trinômio professor/tecnologia/aluno. Na atual sociedade onde o acesso equitativo a informação é gradativamente popularizado, essa se reproduz, circula, modifica e se atualiza em diferentes prismas.

É possível digitalizar sons, imagens, gráficos, textos, enfim uma infinidade de informações. Nesse contexto "a informação representa o principal ingrediente de nossa organização social, e os fluxos de mensagens e imagens entre as redes constituem o encadeamento básico de nossa estrutura social” (CASTELLS, 1999, p. 505).

Bastante amplo o seu significado, a tecnologia, aqui tomada como invenções, criações e descobertas, proporcionou uma mudança profunda nas relações sociais, culturais, políticas, educacionais, econômicas. Não há como negar os benefícios decorrentes das tecnologias para 
a vida dos homens, no seu convívio social e nas estruturas sociais, possibilitando novos conhecimentos, ampliação e alteração nas sociedades.

Novos processos criativos podem ser potencializados pelos fluxos sócio-técnicos de ambientes virtuais de aprendizagens que utilizam o digital como suporte a exemplo, o ciberespaço, a TV digital, enfim essa série de recursos midiáticos que repercutem em nosso meio educacional.Assim, um desafio parece saltar aos olhos: como processar a quantidade de informação que é veiculada? A educação é capaz de mediar esse processo? O uso dessas mídias é realmente garantia de aprendizagem? No ensino é valida essa utilização? Existe um limite para a utilização da máquina enquanto forma de pesquisa?

As mudanças nos processos de trabalho exigem o desenvolvimento de habilidades metacognitivas e de competências para aprender cooperativamente, apoiadas em conteúdos contextualizados e na experiência individual, afinam-se com os propósitos da educação mediada por novas tecnologias. Edgar Morin lembra que hoje, é preciso inventar um novo modelo de educação, já que estamos numa época que favorece a oportunidade de disseminar outro modo de pensamento. Então nada mais oportuno e pleno de possibilidades de expandir essas novas formas e novos pensares.

Quanto a isso, Silva, enfatiza:

\begin{abstract}
“O essencial não é a tecnologia, mas um novo estilo de pedagogia sustentado por uma modalidade comunicacional que supõe interatividade, isto é, participação, cooperação, bidirecional idade e multiplicidade de conexões entre informações e atores envolvidos. Mais do que nunca, o professor está desafiado a modificar sua comunicação em sala de aula e na educação. Isso significa modificar sua autoria enquanto docente e inventar um novo modelo de educação."
\end{abstract}

Uma reflexão sobre o processo de evolução tecnológica conduz inicialmente, a fala (ato tipicamente humano) e a escrita. No período tribal, se sai da comunicação puramente oral para uma comunicação linear, uso de escrita pictográfica e ideográfica, após, uma escrita alfabética, considerada uma tecnologia de informação e comunicação que causou verdadeira revolução na difusão de idéias e informações.

Só no século XIX, os aprimoramentos da tecnologia passam por uma popularização tímida e assim, ampliam as possibilidades de comunicação e informação com a televisão, o rádio, o jornal impresso. Os meios de comunicação de massa provocam as primeiras mudanças em torno de uma comunicação mais democrática e mais acessível. Com a chegada do computador e da internet, essas possibilidades se ampliaram. Um novo momento é festejado.

A não-linearidade, a instantaneidade, a interatividade e a acessibilidade, disseminaramse, permitindo ao mundo, uma globalização de produtos. Essa nova cultura abarcará um novo discurso de valores e modelos preconizados por uma concepção planetária online. A comunicação passa de uma perspectiva do mesmo tempo/ espaço para emissor/receptor para tomar um percurso diferente. Assim, como ocorreu nos séculos anteriores com as inovações tecnológicas, as massas continuaram alijadas desse novo processo. 
E nesse espantoso progresso científico e tecnológico, as tecnologias de informação e comunicação passam por uma ressignificação, pois o ideal é a popularização, pois assim a disseminação de valores e a globalização terão condições de causar os impactos tão desejados, contudo, o campo educacional que deveriam apresentar-se como condição sine qua non para facultar todas as possibilidades e ampliação da tecnologia, dorme em mansas águas.

A educação tem experimentado mudanças na inserção de novas tecnologias nas escolas. Muito se tem discutido sobre novas abordagens metodológicas a partir do uso das tecnologias digitais na educação como mediador do processo ensino-aprendizagem e, vários são os desafios que se colocam, sendo que o principal problema se converge quanto a sua utilização.

O comportamento ingênuo em acreditar que o ato de substituir o giz, o quadro, o caderno, pelo emprego das tecnologias de comunicação e informação irá assegurar o sucesso escolar, não procede, pois se a sua utilização não for planejada dentro duma visão crítica reflexiva, as velhas concepções de ensino aprendizagem assumirão uma faceta de um movimento de modernização conservadora.

O problema estará centralizado na prática pedagógica, apresentando múltiplas possibilidades, consolidada na ação e determinada na nas crenças do professor. Vieira reforça essa idéia ao abordar sobre as tecnologias de informação e comunicação

(...) são os meios, os apoios, as ferramentas que utilizamos para que os alunos aprendam. A forma como os organizamos em grupos, em salas, em outros espaços isso também é tecnologia. O giz que escreve na lousa é tecnologia de comunicação e uma boa organização da escrita facilita e muito a aprendizagem. A forma de olhar, de gesticular, de falar com os outros isso também é tecnologia. O livro, a revista e o jornal são tecnologias fundamentais para a gestão e para a aprendizagem e ainda não sabemos utilizá-las adequadamente. O gravador, o retroprojetor, a televisão, o vídeo também são tecnologias importantes e também muito mal utilizadas, em geral. (VIEIRA, 2003, p. 151).

Para uma prática que surta efeitos pedagógicos esperados, salutar, que se questione qual a concepção de ensino-aprendizagem que é adotada na escola e, consequentemente norteadora da práxis do professor.

Se a tecnologia de comunicação e informação numa nova abordagem é preciso saber escolher, planejar, interpretar, sendo que o principal é pensar num uso consciente. A escola precisa pensar de forma sistemática sobre uma educação de qualidade e, a priori é saber se esse uso é pautada numa visão crítica-reflexiva ou se a tecnologia digital estará sendo usada apenas como uma ferramenta numa perspectiva tradicional.

O uso por si só da tecnologia, não é garantia de sucesso. Assim como o uso apenas do livro didático nunca foi, assim como também a utilização de inúmeros recursos não são garantias de aprendizagem. 


\section{OS IMPACTOS DAS TECNOLOGIAS DE INFORMAÇÃO E COMUNICAÇÃO NOS PROCESSOS EDUCACIONAIS}

Levando-se em conta a diversidade cultural e uma maior participação dos sujeitos nos processos educativos, os desafios encontrados pela educação hoje, são inúmeros. Bem como as propostas mais viáveis de dinamização e efetivação de seus serviços. A exemplo da utilização das mídias numa sociedade ávida de informação, onde se interelacionam culturas, realidades econômicas, sociais, políticas, relações grupais, características individuais, relações interpessoais e de poder, que precisam e devem ser mediadas e bem utilizadas em favor de uma informação e serviços corretos.

Assim, a necessidade de se constituir uma visão diferenciada sobre a tecnologia e sua aplicabilidade,observando a diversidade em torno da questão tecnológica deve basear-se em uma proposta de maior participação dos atores sociais no processo de desenvolvimento social.

Segundo Almeida (1996, p. 25) A integração da tecnologia de informação e comunicação - TIC na educação brasileira já passou por várias fases e traz em sua trajetória uma perspectiva educativa inovadora (Andrade \& Lima, 1993, p.47), que a distingue de ações correlatas de outros países e respectivas políticas para o setor.

No Brasil, o papel atribuído ao computador era o de catalisador de mudanças pedagógicas (Valente e Almeida, 1997, p.11) de uma perspectiva centrada no ensino e na transmissão de informações para uma prática pedagógica voltada à aprendizagem e construção do conhecimento pelo aluno. A inter-relação entre pesquisa, formação e prática pedagógica com as tecnologias de informação e comunicação tem sido a característica básica desde quando se falava em informática na educação.

A informática começou a disseminar-se no sistema educacional brasileiro nos anos 80 e início de 90, do século XX, com uma iniciativa do Ministério da Educação. Inicialmente o MEC patrocinou um projeto, denominado EDUCOM, destinado ao desenvolvimento de pesquisas e metodologias sobre o uso do computador como recurso pedagógico, do qual participavam cinco universidades públicas ${ }^{1}$, nas quais foram implantados centros-piloto para desenvolver investigações voltadas ao uso do computador na aprendizagem (Almeida e Valente, 1997, p.15) ao tempo que realimentavam as práticas em realização nas escolas. Aprende-se a conhecer, aprendendo a fazer e a refletir sobre esse fazer.

O uso da tecnologia trouxe desconforto ao sujeito professor, o desconforto ao perceber que o seu lugar sagrado do conhecimento, não era mais tão sagrado assim, por que não era mais

\footnotetext{
${ }^{1}$ O Projeto EDUCOM foi iniciado em 1985 e encerrado em Federal de Minas Gerais/UFMG, Universidade Federal de Pernambuco, Universidade Federal do Rio de Janeiro/UFRJ e Universidade Federal do Rio Grande do Sul/UFRGS.
} 
imutável e assim sendo, seus princípios e diretrizes mudariam, e essa mudança, desinstalação, geralmente não é bem aceita facilmente nem pelo individuo, nem pelo grupo.

Assim, é necessário ao professor, compreender o que está implicado nestes princípios, que reforça em si mesmo a importância de desenvolver a habilidade de procurar constantemente, dentro e fora do contexto escolar as condições e a percepção da busca do conhecimento, que lhe possibilite o crescimento profissional.

Ainda segundo Silva, a integração da escola com o mundo oportunizada pela inserção das TIC'S, possibilita o uso dos obsoletos "laboratórios de informática" que em certas escolas apenas guardavam equipamentos que ninguém usava, possibilita o acesso da informação a todo corpo escolar, seja ele docente, discente, administrativo, possibilita uma aprendizagem dinâmica e autônoma, produzida sobretudo na interatividade.

\section{O TRABALHO DOCENTE NA ERA DAS TECNOLOGIAS: A IMPORTÂNCIA DA FORMAÇÃO CONTINUADA}

O impacto das novas tecnologias na formação docente é imediato. O professor técnico e repositor de conhecimento perde seu espaço diante dessas tecnologias que exigem cada vez mais do profissional engajamento, participação, conhecimento e preparação. As inúmeras reformas educacionais ao longo dos anos que vem insistindo na formação do professor vêm apontando cada vez mais a necessidade de um profissional crítico-reflexivo com capacitação para mediação de situações, de conflitos e de temas na sala de aula.

Visto que essa agora diante das novas perspectivas de ensino, amplia sua antiga dimensão de quatro paredes e visualiza e abarca um mundo múltiplo, com perguntas a serem feitas e respostas a serem investigadas e formuladas. Um mundo em que o conhecimento está sempre porvir, não suporta mais o professor com respostas prontas. Esse profissional não cabe mais no mercado de trabalho.

Ainda enfrentamos o peso de séculos de uma tendência educacional - não somente no Brasil - que tinha o objetivo principal de formar mão de obra para a expansão industrial e capitalista em franco desenvolvimento. No entanto, políticas e ações educacionais têm ainda enfrentado algumas questões diretamente ligadas ao contexto socioeconômico de uma forma pouco crítica, incorporando discursos e debates como, por exemplo, o da ênfase no aprender a aprender, que segue na esteira dos pilares desenvolvidos por Delors no Relatório para a Unesco da Comissão Internacional sobre Educação para o Século XXI (DELORS, 1998, apud GOUVÊA, 2003,p.18).

Nóvoa (1992, p.25, apud Silva , 2009,p.14), propõe a formação de professores numa perspectiva que denomina crítico-reflexiva, que "forneça aos professores os meios de um 
pensamento autônomo e que facilite as dinâmicas de autoformação participada, com vista à construção de uma identidade profissional". Assim, considera três aspectos na formação docente: produzir a vida do professor (desenvolvimento pessoal), produzir a profissão docente (desenvolvimento profissional) e produzir a escola (desenvolvimento organizacional).

Quanto ao desenvolvimento pessoal, que seria o produzir a vida do professor, o autor destaca a necessidade de uma interação entre os saberes adquiridos e a própria experiência de vida do professor a serem consideradas, ambas como construtores de sua aprendizagem e portanto, ambas passíveis de igual valorização.

$\mathrm{Na}$ produção de sua profissão docente, o autor propõe que o professor deve ser responsável pela produção do seu próprio conhecimento, desde a atuação como agente na implementação das políticas educacionais, como também quanto gerente desse conhecimento que deve ser construção de uma prática reflexiva e direcionada para a atuação no espaço hoje múltiplo e plural que é a escola.

Por fim, munido das experiências adquiridas, as produzidas em serviço e orientado por uma visão política e ampliada do processo, esse professor vai produzir a escola que ao mesmo tempo que terreno onde os saberes se processam e se formam, configura-se em terreno, onde os caminhos são questionados, polemizados, refletidos, reestruturados e refeitos. Sendo assim o fim e o próprio processo.

Nessa perspectiva de Nóvoa, o uso da tecnologia funciona como uma ferramenta essencial nesse processo, uma vez que inaugura em si a possibilidade da formação continuada e em serviço do professor e mais ainda, sua autonomia perante o processo do reaprender.

Para Almeida (1996,p.78)

\begin{abstract}
Na inter-relação entre pesquisa, formação de professores e prática pedagógica com o uso da TIC, a área de conhecimento tecnologia em educação se realimenta, se transforma e avança a partir dos resultados das investigações e novos conhecimentos produzidos. Um dos aspectos que mudou de forma substantiva nos últimos anos foi a formação de professores para o uso das TIC na prática pedagógica tendo em vista a ênfase das atividades atuais na formação contextualizada na realidade da escola e na atuação do professor.
\end{abstract}

Esse novo fazer se manifesta com o professor em formação, por que este vivencia os conflitos e desequilíbrios inerentes ao sujeito da própria aprendizagem e tem a oportunidade de recontextualizar essa vivência para a sua prática pedagógica permitindo ao aluno a sua expressão que por ser imprevisível, permite a compreensão e/ou a reconstrução do saber. 


\title{
O PAPEL DO EDUCADOR E DO EDUCANDO
}

Como dentro dessa perspectiva o conteúdo não perde sua importância, o papel do professor que há muito não é mais de detentor do conhecimento, é de mediador desse, uma vez que é o facilitador de conceitos. Seu papel agora consiste em ampliar esses conceitos, informações, procedimentos e regras, procurando identificar aquilo que é significativo para o aluno e criando situações que favoreçam transformar os conhecimentos do senso comum em conhecimento científico.

O rigor científico é necessário, mas não pode ser ponto de partida. Da mesma forma, é preciso compreender as novas formas de produção da escrita e acesso à leitura propiciadas pelas TIC para utilizar seu potencial na escola. Talvez o papel do professor aqui tenha se ampliado também, porque esse trabalho ao requerer empenho, dedicação, acaba requerendo paixão, por que produzir esse tipo de conhecimento interativo gera maior responsabilidade.

Com o uso de TIC e ambientes virtuais de aprendizagem o professor passa a ser tão aprendente quanto o aluno, situação que desastibiliza, mas enche de coragem aqueles tentados aos desafios. A aprendizagem é mútua, dinâmica, incessante, integrada, colaborativa, compartilhada. A correção e a avaliação aqui tomam outra dinâmica e portanto, outra dimensão. Não há que se perder o rigor científico, Ao contrário, a ciência abre-se em informações, possibilidades e referências que o professor aprendente também irá descobrir. Um outro fator que essa mediação possibilita é o desenvolvimento de relações mais próximas, mais humanas, mais afetivas entre professor e aluno, fator esse que certamente contribui e muito para a aprendizagem.

\begin{abstract}
Nessa aventura, o professor também é desafiado a assumir uma postura de aprendiz ativo, crítico e criativo, articulador do ensino com a pesquisa, constante investigador sobre o aluno, seu nível de desenvolvimento cognitivo, social e afetivo, sua forma de linguagem, expectativas e necessidades, seu estilo de escrita, seu contexto e cultura. O professor é um artista que busca projetar as bases de um currículo intrinsecamente motivador para o aluno tornar-se leitor e escritor. Não é o professor quem planeja para os alunos executarem, ambos são parceiros e sujeitos do processo de conhecimento, cada um atuando segundo o seu papel e nível de desenvolvimento. (Almeida,2000, p.12).
\end{abstract}

E aqui quando se fala em motivação, volta-se a lembrar que nem recursos, nem professor sozinhos podem conseguir "o milagre" de ter um aluno engajado e comprometido com seu próprio aprender, mas a boa dosagem de ambos professor articulador e criativo, com os recursos certos, farão total diferença no espaço escolar e para o aluno em questão. 
O perfil do aluno muda como muda o perfil da sociedade. Certamente a velocidade dessas mudanças fazem com que a criança de hoje não aprenda da mesma forma que a de 20 anos atrás. Esse aluno que é um ser novo, em todos os aspectos falando, em seu estado biológico, em seu estado de recepção intelectual e cultural, portanto, um aprendiz em potencial, ávido de novidades que a própria dinâmica atual supõe.

Um mundo dinâmico, que renova-se, repagina-se, com uma velocidade que ninguém ousa supor acompanhar e com uma riqueza de sons e visões que seduz a todos. Mas que por isso mesmo, precisa ser melhor orientado, melhor trabalhado e melhor cuidado. O mundo abrese em informações e possibilidades, mas essas por vezes são um terreno inseguro e perigoso. As mídias e tecnologias também proporcionam isso: conhecimento não-mediado, pode tornarse um inimigo feroz do processo de crescimento e aprendizagem.

\section{OS NOVOS RECURSOS TECNOLÓGICOS DISPONÍVEIS NO ESPAÇO ESCOLAR}

Vivemos numa época sui generis, onde algumas escolas compartilham o antigo quadro de giz, mas possuem laboratório de informática com computadores adaptados para deficientes visuais. Mas esse mesmo quadro de giz, compartilhou há alguns anos atrás (não muitos), a máquina de datilografar no sistema Braille e/ou os livros também no mesmo sistema. Recursos novos? Sim. Professores e Gestores preparados? Nem sempre. Aluno aprendendo? Talvez.

Os recursos tecnológicos remontam aos primórdios da comunicação, e deve ser considerada segundo os meios que essa geração utilizava. Sendo assim, Santos, (2006) apud PEREIRA 2007, p.67) categoriza da seguinte forma:

$1^{\circ}$ Geração: baseados no meio texto, impressos e escritos à mão;

$2^{\circ}$ Geração: Utilizava a televisão e o rádio;

$3^{\circ}$ Geração: trouxeram os sistemas de primeira e segunda geração juntos, em uma abordagem multimídia, com base em textos, áudio e televisão. Entretanto a transmissão tendia a ser usada como um meio suplementar de apoio ao material impresso;

$4^{\circ}$ Geração: foram desenvolvidas em torno de comunicações mediadas por computador, Internet, bibliotecas virtuais e etc.

Considerando essas informações, todas as gerações enfrentavam o deslumbramento/desconfiança ante os recursos de sua época, e certamente também discutiam sua validade, eficiência, eficácia e com certeza também enfrentavam as resistências dos profissionais na aprendizagem e atualização. Mas talvez, nenhuma dessas tenha tido o impacto 
da utilização do computador. Incrível que, há mais de 10 anos de sua franca utilização em todos os espaços, ainda haja desconfiança, resistência e preconceito quanto ao seu uso didático.

O desenvolvimento das comunicações mediadas por computador e à utilização de diversos recursos ligados as tecnologias da informação e comunicação, só aparecem a partir do desenvolvimento da internet na chamada $4^{\mathrm{a}}$. geração. Destacando os recursos multimídias, conferência por computador, correio eletrônico e a utilização da Internet que possibilitou ainda o acesso a banco de informações, pesquisas, acessos a bibliotecas virtuais, etc.

O cruzamento e a valorização da comunicação interpessoal com a, da comunicação midiática, da comunicação grupal e organizacional, bem como a necessidade reiterada da interdisciplinaridade, são noções que vêm sendo exploradas e bem utilizadas em estudos já bastante avançados em países como Estados Unidos, Espanha e França, entre outros, apresentando resultados edificadores no que concerne ao bem-estar dos povos e de seu desenvolvimento auto-sustentável.

$\mathrm{O}$ acesso popularizado à Internet faz surgir as chamadas comunidades virtuais, que passaram a ser utilizadas na educação a distância, por aqueles indivíduos que possuem interesses comuns, ou objetos de estudo comuns favorecendo assim a resolução de problemas, discussão e aprendizagem tornando-se assim um grupo de pessoas reunidas virtualmente formando uma assim uma comunidade com finalidade específica de aprendizagem

A difusão dessa utilização fez com que, pesquisadores, universidades e até empresas começassem a planejar programas que sendo utilizados pela Internet promovessem a interação e a integração dos usuários. A primeira das exigências é que o ambiente permita, e até obrigue, uma interação muito grande do aprendiz com o objeto de estudo. Essa interação, contudo, não significa apenas apertar teclas ou escolher opções de navegação.

A interação deve ultrapassar isso, integrando o objeto de estudo à realidade do sujeito, dentro de suas condições, de forma a estimulá-lo e a desafiá-lo, ao mesmo tempo permitindo que novas situações criadas possam ser adaptadas às estruturas cognitivas existentes, propiciando o seu desenvolvimento. A interação deve abranger não só o universo aluno e computador, mas, preferencialmente, também o aluno e professor, com ou sem o computador (FERREIRA, 2001, p.33).

Deve-se sobremaneira constar que acima de tudo é também um trabalho de inclusão. A inclusão midiática, é um processo que visa a transformação do sujeito e sendo assim entender essa nova abordagem e saber utilizá-la é um processo de interação que exige do sujeito empenho, dedicação e compromisso, uma vez que este é o maior impasse da educação: o saber cristalizado que dificulta a abertura às novas aprendizagens. Não é subordinar as ações à comunicação ou à tecnologia, mas integrá-las num todo operacional onde forma e conteúdo possam trabalhar juntas. 
A descrição da Resolução CEE n ${ }^{\circ} 79$, de novembro de 2008 diz no artigo primeiro que a EAD "refere-se ao processo de ensino e de aprendizagem no qual professores e alunos, ainda que estando separados fisicamente no espaço e/ou no tempo, utilizam, na mediação didáticopedagógica, tecnologias de informação e de comunicação tais que garantam a interlocução entre os sujeitos do processo, em tempo real ou não".

Com suas bases legais estabelecidas na Lei de Diretrizes e Bases da Educação Nacional $\mathrm{n}^{\mathrm{o}}$ 9394, de 20 de dezembro de 1996, Decreto 5622, a EADtem a possibilidade de realizar a inserção social, disseminação do conhecimento individual e coletivo bem como ajudar na construção de uma sociedade mais justa e igualitária. Este é o ponto que faz da universidade uma formadora de cidadãos conscientes de seu papel sócio político.

Nesta modalidade de educação a interação entre professor e aluno acontece intermediada por tecnologias telemáticas (comunicação à distância de um conjunto de serviços informáticos através de uma rede de telecomunicações), como a internet e outras hipermídias, como também utilizando correspondências, rádios, televisão, mídias óticas e outras tecnologias.

As possibilidades de utilização são inúmeras, e em todas as disciplinas, mas uma de suas características principais é que estabelece uma comunicação de múltiplas vias e suas possibilidades ampliaram-se com a evolução tecnológica vencendo os últimos obstáculos (tempo e espaço).

Assim, poor mais que a $\mathrm{EaD}$ seja vista como ferramenta que atinge pessoas nos locais mais diversos, é necessário que haja interatividade entre os agentes do processo de ensino e aprendizagem, este, a fim de superar o fator geográfico que pode separar esses agentes. Além de ser um pressuposto este dado também está contido na Resolução do CEE.

À medida em que a educação deixa de ser percebida como apenas a transferência de informações do professor para o aluno e sim como disseminadora de assuntos que precisam ser contextualizados a realidade do aluno, temos na educação a distância o desafio que leva o discente a pesquisar e entender o conteúdo como forma de praticar o conhecimento e participar da disciplina.

Nesta modalidade de ensino deve-se observar que não é a metodologia de ensino que deve mudar, mas sim a comunicação. Essa afirmação relata que não adianta o uso de tecnologias avançadas para garantir um ensino de qualidade. $\mathrm{O}$ uso das multimídias terão o alcance que a comunicação entre os interlocutores permitirem. E é nesse sentido que as possibilidades de utilização podem ser ampliadas, ou podem ser mínimas pois o uso das tecnologias não dispensa a ação humana e é a criatividade e interatividade que vão definir o sucesso dese trabalho. 


\section{A PRÁTICA PEDAGógICA}

Como toda e qualquer prática inovadora, a utilização das multimídias causam resistências no meio educacional. A princípio é uma reação natural do ser humano a desconfiança com o novo, e depois por desconfiança talvez de sua real utilidade, eficiência e eficácia no processo educativo já tão prejudicado nos dias atuais, principalmente pelo bombardeio de projetos, programas que não estão resolvendo o problema da educação pública. Certamente tais tecnologias têm auxiliado, o processo de ensino e talvez o de aprendizagem, mas o resultado tem sido pouco observável na prática e a educação formal continua essencialmente inalterada

Ainda que com o desenvolvimento e introdução das tecnologias, observa-se um lento e gradual avanço, há ainda muitos desconfiados em relação a todo esse processo que no Brasil soma cerca de 20 anos e que porém segundo especialistas vem sempre sendo feita de forma massificada, sem o acompanhamento de uma reflexão necessária para a adequação com a forma de ensino-aprendizagem que aí está.

O que temos hoje é uma educação massificada, onde os alunos são aprovados indiscriminadamente e numa escola com sequência de disciplinas alheias ao ser humano, como se esse fosse apenas mais um produto a ser preenchido com as necessidades do seu meio. Os conhecimentos acumulados são despejados em suas cabeças formando alunos sem maior capacidade para absorção de fatos e processos e submisso ao sistema de acumulação e produção indiscriminadas. Aqueles que não se adéquam a isso certamente estarão fora e desvinculados desse processo. Nesse sentido entra em choque com o verdadeiro papel da educação que é o da inclusão.

Assim a educação não tem somente que adaptar às novas necessidades dessa sociedade do conhecimento, mas tem que assumir um papel de ponta nesse processo. Com a contínua diversificação e desenvolvimento dos recursos tecnológicos de comunicação e informação e sua presença iminente na vida cotidiana de todos os cidadãos, esses não podem ser ignorados pela escola, mas há que haver uma coerência em sua inserção, pois apesar de não serem indispensáveis ao processo educativo, a sua utilização indiscriminada e incoerente pode dificultar aquilo que viria a facilitar, a aprendizagem.

É essa a premissa maior da introdução das novas tecnologias na educação, de que ela venha a facilitar. Dessa maneira a utilização das Novas Tecnologias em Educação -NTICs está fundamentada em uma concepção pedagógica Behaviorista, onde aprender significa incorporar e utilizar um comportamento apropriado. Portanto, o objetivo principal da educação seria treinar os estudantes a mostrar um determinado comportamento e controlá-lo externamente. 
Uma tendência pedagógica é, na verdade, uma inclinação por pensamentos e comportamentos pedagógicos lidos na história da educação ou mesmo em outras práticas pedagógicas hodiernas. Muitas vezes, em uma escola, em uma comunidade, percebem-se práticas educativas cuja orientação embora existente não é fruto de uma reflexão mais apurada, condensada. Assim, vão-se reproduzindo e tornam-se explicações do processo educativo, enraizando-se na dinâmica escolar. Por seu caráter provisório, já que demandam uma maior reflexão, estas orientações são consideradas tendências. Se fruto de análise, de pesquisas, de estudo passam desta configuração ao status de uma teoria, de uma proposta educativa. (FERREIRA,2001,02)

Assim, o uso das NTICs deve ter como objetivo mediar a construção do processo de conceituação dos alunos, buscando a promoção da aprendizagem e desenvolvendo habilidades importantes para que ele participe da sociedade do conhecimento e não simplesmente facilitando o seu processo de ensino e de aprendizagem.

Para que as NTICs promovam as mudanças esperadas no processo educativo, devem ser usadas não como máquinas para ensinar ou aprender, mas como ferramenta pedagógica para criar um ambiente interativo que proporcione ao aprendiz, diante de uma situação problema, investigar, levantar hipóteses, testá-las e refinar suas idéias iniciais, construindo assim seu próprio conhecimento.

É claro que elas ampliam as possibilidades em sala de aula, mas não são definitivas. Os autores como Perrenoud (2001), Shon (2000), Nóvoa (2000), Zeichner (1993) nos remetem a discussão sobre a prática reflexiva e a participação crítica como orientações prioritárias na formação de professores. É nesse sentido que a escola e os professores não podem ficar imóveis a esses contextos sociais em transformação.Precisam discutir, definir e não apenas aceitar e incorporar.

A utilização desses meios na educação não garantirá por si só a aprendizagem dos alunos, pois as mesmas são instrumentos de ensino que podem e devem estar a serviço do processo de construção e apropriação do conhecimento dos aprendizes e não a educação e ensino colocadas a seu serviço. A introdução desses recursos na educação deve ser acompanhada de uma sólida formação dos professores para que eles possam utilizá-las de uma forma responsável e com potencialidades pedagógicas verdadeiras, não sendo utilizadas como máquinas divertidas e agradáveis para passar o tempo.

Para que o verdadeiro papel dessas tecnologias seja delimitado, é necessário um trabalho setorizado, uma análise da vida escolar ao nosso redor, sob o ponto de vista das orientações que determinam a prática educativa nos remete a identificarmos tendências ou paradigmas consciente ou inconscientemente determinantes na linguagem, nas ações, nos instituídos garantindo esta ou aquela configuração escolar.

Entender esta configuração é deslindar estes pressupostos, compreendendo-os em seu momento e nas determinações históricas que os configuraram.É a análise da nossa proposta de educação, da proposta que a escola defende, para ai observar, refletir, e escolher o papel e o raio de ação que o as novas tecnologias devem ter. 
De acordo com Perrenoud

\begin{abstract}
A autonomia e a responsabilidade de um profissional dependem de uma grande capacidade de refletir em e sobre sua ação. Essa capacidade está no âmago do desenvolvimento permanente, em função da experiência de competências e dos saberes profissionais. Por isso, a figura do profissional reflexivo está no cerne do exercício de uma profissão, pelo menos quando a consideramos sob o ângulo da especialização e da inteligência no trabalho. (2002, p.13)
\end{abstract}

O trabalho em si envolve toda a escola, e deve partir da análise do Projeto Político Pedagógico, desde lá deve se delimitar esse papel das novas tecnologias como um todo. Em conseqüência é necessário que o professor defina suas ferramentas teóricas, estabeleça pontos de referências com os quais poderá exercer sua dimensão hermenêutica: atribuir sentidos, produzir interpretações do que vive nas ações pedagógicas desenvolvidas, inserindo-as em uma vertente teórica e tendo condições de propor a continuidade de uma reflexão-ação sobre seu projeto educativo.

Vale dizer, ao educador cabe analisar informações e teorias, construir um todo de conhecimentos sólidos para fundamentar suas práticas pedagógicas. Na verdade, ao educar, o educador já está produzindo uma prática geradora de uma teoria pedagógica, posto que esta constitui aquela, de forma a não se saber onde começa uma e onde acaba a outra. Pensando assim que se propõe, a seguir, uma leitura de algumas tendências e paradigmas orientadores das práticas educativas, tais como são lidas na realidade. Se as novas tecnologias são a tendência do momento, há que se avaliar, estudar para poder utilizar.

\title{
CONSIDERAÇÕES FINAIS
}

De acordo com Penin \& Vieira (2002, In: VIEIRA, 2002) a escola sofre mudanças relacionando-se com os momentos históricos. "Sempre que a sociedade defronta-se com mudanças significativas em suas bases sociais e tecnológicas, novas atribuições são exigidas à escola". (p13). Assim, o papel da escola deve estar de acordo com os interesses da sociedade atual, ou seja, a escola precisa assumir as características de uma instituição que atenda às exigências geradas por esses fatores. Sendo assim, a gestão da escola precisa se empenhar para reestruturar a escola, pois a aprendizagem agora ocupa toda a vida das pessoas, além da escola, adquirem-se conhecimentos em diversos espaços, no familiar, no social e no virtual.

Ainda em Soares (2002), voltar o olhar para dentro da escola significa conhecer em que medida e dimensões culturais, sociais, tecnológicas criam ou estimulam o trabalho de alunos, professores e direção. Assim, é possível buscar formas de promover uma educação includente por meio da minimização dos efeitos perversos de uma sociedade hierarquizada. 
Para que a escola consiga enfrentar mudanças significativas que elevem o padrão da escola, é preciso que ocorra uma mudança radical na atitude das pessoas, com o objetivo de que as mesmas passem a encarar a inovação como um desafio e sintam-se estimuladas pela motivação pessoal e, assim, se tornem capazes de ir além dos seus próprios limites. "Atitude é uma predisposição subliminar da pessoa, resultante de experiências anteriores, da cognição e da afetividade, na determinação de sua reação comportamental em relação a um produto, organização, pessoa, fato ou situação".

A busca por uma educação humanista, onde a diversidade seja percebida como uma dimensão complementar e não antagônica, provocando uma série de estudos que buscam refletir sobre o universo escolar como um fenômeno total, não mais determinado por uma ou outra dimensão (econômica, social e cultural), mas pela forma como estas dimensões afetam o cotidiano escolar.

E essa postura é ainda mais proeminente quando se trata da questão de inserção de novas tecnologias que alteram e afetam o cotidiano da escola na medida que introjetam novas formas de ação que sempre requerem responsabilidade, conduta e mudança de paradigmas.

Nesse sentido, necessita ter motivação, responsabilidade, dinamismo, criatividade e capacidade de atender às necessidades mais urgentes. Isso requer um constante aprendizado, para também atualizar-se e conhecer as mais recentes contribuições dos educadores sobre os processos de capacitação de lideranças educacionais. 


\section{REFERÊNCIAS}

ALMEIDA, M. E. ProInfo: Informática e formação de professores. Secretaria de Educação a Distância. Brasília: Ministério da Educação, SEED. Vol. 2, 2000a.

ALMEIDA, M. E. B. O computador na escola: contextualizando a formação de professores. São Paulo: Tese de doutorado. Programa de Pós-Graduação em Educação: Currículo, Pontifícia Universidade Católica de São Paulo, 2000b.

ALMEIDA, M. E. Informática e Educação. Diretrizes para uma formação reflexiva de professores. São Paulo. Dissertação de Mestrado. Programa de Pós-Graduação em Educação: Supervisão e Currículo, Pontifícia Universidade Católica de São Paulo, 1996.

ANDRADE, P. F. \& Lima, M. C. M. Projeto EDUCOM. Brasília: MEC/OEA, 1993.

ANDRADE, M. M. Introdução a Metodologia do Trabalho Científico: elaboração de trabalhos de graduação. 6. Edição. São Paulo: Atlas, 2003.

ANDRADE, R. C. de. Introdução: Gestão da Escola. In: ANDRADE, Rosamaria

Calaes de (org.); ACÚRCIO, Marina Rodrigues B. (coord.). A gestão da escola. Porto

Alegre/Belo Horizonte: Artmed/Rede Pitágoras, 2004 (Coleção Escola em ação; 4).

FREIRE, Paulo. Pedagogia do oprimido.12ª edição. Rio de Janeiro: Paz e Terra, 1983.

Monitor educacional. Disponível em:

http://educar.sec.ba.gov.br/monitoreducacional/index.php>. Acesso em 30.05.2011

MORAN, José Manuel; MASETTO, Marcos; BEHRENS, Marilda Aparecida. Novas Tecnologias e Mediaç̃o Pedagógica. Campinas: Papirus, 2000.

MORAN, José M. Como utilizar as tecnologias na escola. Disponível em: < http://www.eca.usp.br/prof/moran/utilizar.htm>. Acesso em: 01.06.2011.

As mídias na educação. Disponível em: < http://www.eca.usp.br/prof/moran/midias_educ.htm>. Acesso em: 01.06.2011.

NÓVOA, A. Formação de professores e profissão docente. In: A. Nóvoa (org.). Os professores e sua formação. Lisboa: Nova Enciclopédia, 1992.

, A. Os professores e sua formação. Lisboa, Dom Quixote, 1992. Profissão professor.2.ed.Porto,Porto Editora, 1995

OLIVEIRA, M. K de In: La Talle, Y et alii. Piaget, Vygotsky, Wallon: teorias psicogenéticas em discussão. São Paulo, Summus, 1992. 
PERRENOUD, P. H. Práticas pedagógicas, profissão docente e formação. Perspectivas sociológicas. Lisboa, Publicações Dom Quixote, 1993.

Dez novas competências para ensinar. Porto Alegre, Artes Médicas, 1999a. Construir as competências desde a escola. Porto Alegre: Artmed, $1999 \mathrm{~b}$.

PIMENTA, Selma G. (org.). Saberes pedagógicos e atividade docente. 2 ed. São Paulo: Cortez, 1999.

VALENTE, J. A. \& Almeida, F. J. (1997). Visão Analítica da Informática no Brasil: a questão da formação do professor. In Revista Brasileira de Informática na Educação-SBIE, $\mathrm{n}^{\mathrm{o}} 1$.

VALENTE, J. A. (org.). Computadores e Conhecimento: repensando a educação. Campinas/SP: Gráfica Central da UNICAMP, 1993. 